\title{
Electric Vehicle Battery Modelling and Simulation Using MATLAB-Simulink
}

\author{
Dr. A. Srujana ${ }^{a}$, Mrs. A. Srilatha ${ }^{b}$, Mr. S. Suresh ${ }^{\mathrm{c}}$ \\ a,b,c Department of Electrical and Electronics Engineering, VidyaJyothi Institute of Technology \\ Aziz Nagar Gate, C.B.Post, Hyderabad - 500075 \\ srujanaeee@vjit.ac.in ${ }^{\mathrm{a}}$, asrilathaeee@ vjit.ac.in ${ }^{\mathrm{b}}$, sureshshamanety@vjit.ac.in ${ }^{\mathrm{c}}$
}

Article History: Received: 10 November 2020; Revised 12 January 2021 Accepted: 27 January 2021; Published online: 5 April 2021

\begin{abstract}
Electric vehicles ( EVs) are an alternate means of transport for future as they have great potential to minimize the use of petrol based and other transport fuels that emit high $\mathrm{CO} 2$. The components of the BEV framework were discussed here, and a battery electric vehicle (BEV) model was simulated on MATLAB-Simulink. Also, the related components of the electrical system and its corresponding verification equations have been established. In addition, all simulation outcomes were considered. This research provides a basis for further research.
\end{abstract}

Keywords: Mathematical Modeling, MATLAB-Simulink, Battery Electric Vehicle, state of charge, battery management system

\section{Introduction}

Energy conservation is one of the main problems that the climate faces in the world. The global energy climate faces many threats as well. No one identifies the upcoming of energy correctly, we trust that transport play a major role in saving future energy [1]. Currently, EVs are the products of technical innovation which have contributed in making our lives simpler and safer. Not only do EVs consume energy, they too generate electricity, store, and transport. This makes them an outstanding fuel vehicle option. In addition, comparison to conventional cars which use diesel fuel, which are efficient and eco-friendly which have a storage unit [2]. MATLABSimulink used to design the BEV components and integrate whole structure. In addition, the BEV model and its equations were simulated. The simulation of BEV and its components of the electrical system were discussed in this paper. Furthermore, it explores all consequences of simulation. In [10] the Author discussed the efficient battery modelling using different Evolutionary algorithm The engine, electric motor, battery charge controller, driving cycle, driver model and longitudinal vehicle Dynamic Model.

\section{Batteryelectric Vehicle Components}

\section{A. Transmission model}

The model directs the changing necessities of the vehicle during the change of gear. It transfer torque from the model of the engine and the braking force from the model of the driver to the front and rear traction forces. The inputs of the longitudinal vehicle dynamic model [3].

$$
\left(J+m \times k \times \tau \times R_{\text {Tire }}\right) \frac{d w_{M G}}{d t}=T_{M G}+T_{P S D}+T_{r}
$$

$\mathrm{J}$ - rotor inertia of MG rotor, $\mathrm{m}$ - vehicle mass, $\mathrm{k}$ - transmission ratio, which is $0.256, \mathrm{x}$ is equal to $2.72 \mathrm{x} 10^{-}$ ${ }^{2} R_{\text {Tire }}$ tire radius, $\mathrm{dw}_{\mathrm{MG}} / \mathrm{dt}$ is the derivative of $\mathrm{MG}$ rotation speed, $\mathrm{T}_{\mathrm{MG}}$ is the torque developed by $M G, \mathrm{~T}_{\mathrm{PSD}}$ is output of Power Split Device (PSD) torque, and $\mathrm{T}_{\mathrm{r}}$ is the resultant torque.

\section{B. Model of Electric Motor}

In BEV, hasa important function. Made on a DC motor [3], the resulting motor features have been developed.

\section{Speed Control Of Motor}

The speed of engine can be calculated at the instruction voltage of various speed methods. As seen in the equation below, an input to the motor controller. 


$$
W v=\alpha U+b
$$

Where U - characteristic curve approximating a line, Wv- instruction voltage of the motor speed control, a and $\mathrm{b}$ are coefficient of equation that varies as motor load changes.

\section{Regenerative Braking}

The moving energy of vehicle is captured by the regenerative braking tool and then transformed and feed back into the source of the battery, electric power.

$$
W_{c}=\frac{1}{\eta_{c}}\left(\frac{m v^{2}}{2}+m g h\right)
$$

Where $\mathrm{W}_{\mathrm{c}}$ is stored Energy in the vehicle's control source, $\mathrm{m}$ is vehicle mass, $\mathrm{V}$ is Vehicle speed, $\mathrm{h}$ is Maximum height change of the BEV, and nc is Energy efficiency of the power source.

\section{Charge Controller Model of Battery}

This is in charge for the longevity of the batteries. In designing the BEV's electrical system, it is essential to use an real battery management system (BMS). Battery voltage, current, temperature, state of charge (SoC), calculation, and cell battery, includes a basic battery pack. The SOC is found by the equation [4]

\section{Battery Pack}

It consists of $\mathrm{M}$ modules in parallel; each module contains elements called "cells" associated to the $\mathrm{N}$ array

$$
S O D=\frac{1}{Q_{T}} \int_{0}^{t} \alpha[i(\tau)] \cdot \beta[T(\tau)] d_{\tau}
$$

SOD - state of discharge, $\mathrm{t}$ - time, $\mathrm{T}$ - temperature, and i-current.

\section{State of Charge}

The remaining capacity of battery may be affected by temperature is expressed as a percentage, Level of discharge and life of the battery. The ratio of the residual charge, as the equation below illustrates, the SoC is the nominal power.

$$
S o C=\frac{Q(t)}{Q_{\text {nom }}}
$$

Where the ratio between the available residual charges is $\mathrm{Q}(\mathrm{t})$ and the nominal power is $\mathrm{Q}$ nom.

\section{Driving Cycle}

The schedule of vehicle operations that illustrates the choice of speed and gear as a function during simulation, period. Driving cycles to test the fuel economy and vehicle efficiency of small cars in cities [4], the mode for small cars in cities was selected.

\section{E. Driver Model}

The driver model considers the model to create an acceptable throttle and break command through the PI controller. Impartial speed and the true speed of the present. A feedback loop of vehicle is used to safeguard correct position speed monitoring by the vehicle. Vehicle velocity is used. The command from throttle to the driver model is given by the electric motor, Transmitted to torque and an input to the mode of transmission mode

\section{F. Vehicle Dynamic Model Longitudinal}

The vehicle dynamic of longitudinal, the car, tyres, roadway and driving system defined as model. There are three variables for the movement dynamics model status of electric car: wheel slip in longitudinal direction, centre of gravity of the vehicle speed, and circumferential speed of the wheel. It is important to recognise the acting forces in the direction of a vehicle in order to monitor its actions in motion [5].

$$
\lambda_{x}(t)=\frac{V_{v(t)}-V_{k}(t)}{V_{v(t)}}
$$

the longitudinal slip of the drive wheel is hs $(t)$, the speed of the electric vehicle is $V_{V}, V_{k}$. 


\section{Methodology}

MATLAB-Simulink is used to design the components of the EV battery and incorporate the entire device. In addition; MATLAB-Simulink is used to model the EV's battery and the equivalent equation for the electric vehicle Confirmation. MATLAB is a language of computing that in one setting assimilates programming, computing and visualisation. To resolve engineering and science problems, it has been expanded and used in several domains. MATLAB has a rich and strong graphical toolbox that allows the user to function in a convenient and easy atmosphere [6].

\section{Specifications}

the specifications of Car used[4]. Table I shows the parameters

Table 1. Drive train Parameters of

\begin{tabular}{|l|l|}
\hline Drive train Parameters \\
\hline Battery Drive & Lithium-Ion $(2.8 \mathrm{~V})$ \\
\hline Modules, cells & 3.1 \\
\hline Voltage & 200.5 \\
\hline Capacity & $26.881 \mathrm{kWh}, 122 \mathrm{Ah}$ \\
\hline Weight of Battery & $276 \mathrm{~kg}$ \\
\hline Lifetime & 11 years $\backslash 170,000 \mathrm{~km}$ \\
\hline Motor & PMAC $($ YASA-400) \\
\hline Output & $90.02 \mathrm{KW}$ \\
\hline Torque & $370 \mathrm{Nm}$ \\
\hline Transmission & Single Speed 3.37:1 \\
\hline
\end{tabular}

\section{BEV Simulation}

To model BEV, all mathematical equations applied to each part in the BEV simulation have been selected. Six components are included in the simulation model: the transmission model, motor model, controller model for battery charge, driving cycle, driver model and longitudinal model vehicle dynamics, as revealed in Figure1.

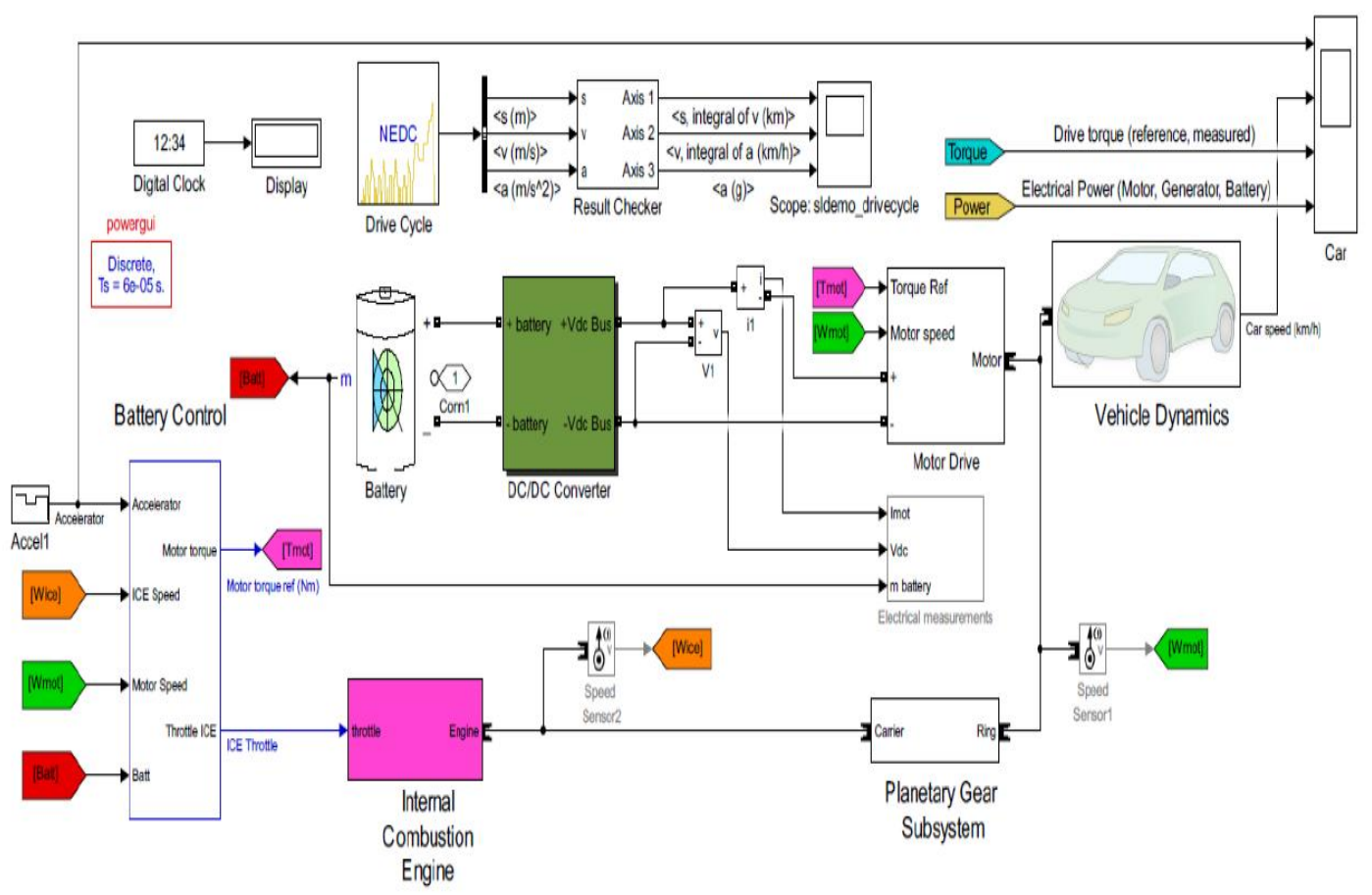

Figure1. Simulation of Battery Electric Vehicle

\section{Results}

As in Figure1 the mathematical equations used by all subsystem blocks have generated the BEV simulation model. In addition, the outcome shown in Figure 2 and Figure 3 reflects the battery voltage, current \& capacity, and charging state of the battery. All the data shows the simulation is running in a successful state. Also, the Latest Driving Cycle was choosen to quantify the amount of emissions from engine and fuel economy in Indoor 
City in Figure2, the battery's voltage, current and power are revealed. The battery current curve follows the shape of the motor current and the torque curves, as shown in the figures below. We observe rise of battery current with increase in torque demand. In addition, power is drawn from battery power curve to load during motoring, and then returns to battery during regeneration when the polarity of the voltage and the current are equal, the motor will operate in a normal motoring mode.Also, the current turns negative and power flows in the opposite direction and motor switches to the regenerative braking mode. The charge state of the battery (SOC) is the ratio between the residual power and the full capacity. As shown in Figure 3, SOC has a low depleted charge, which is good for fuel economy.
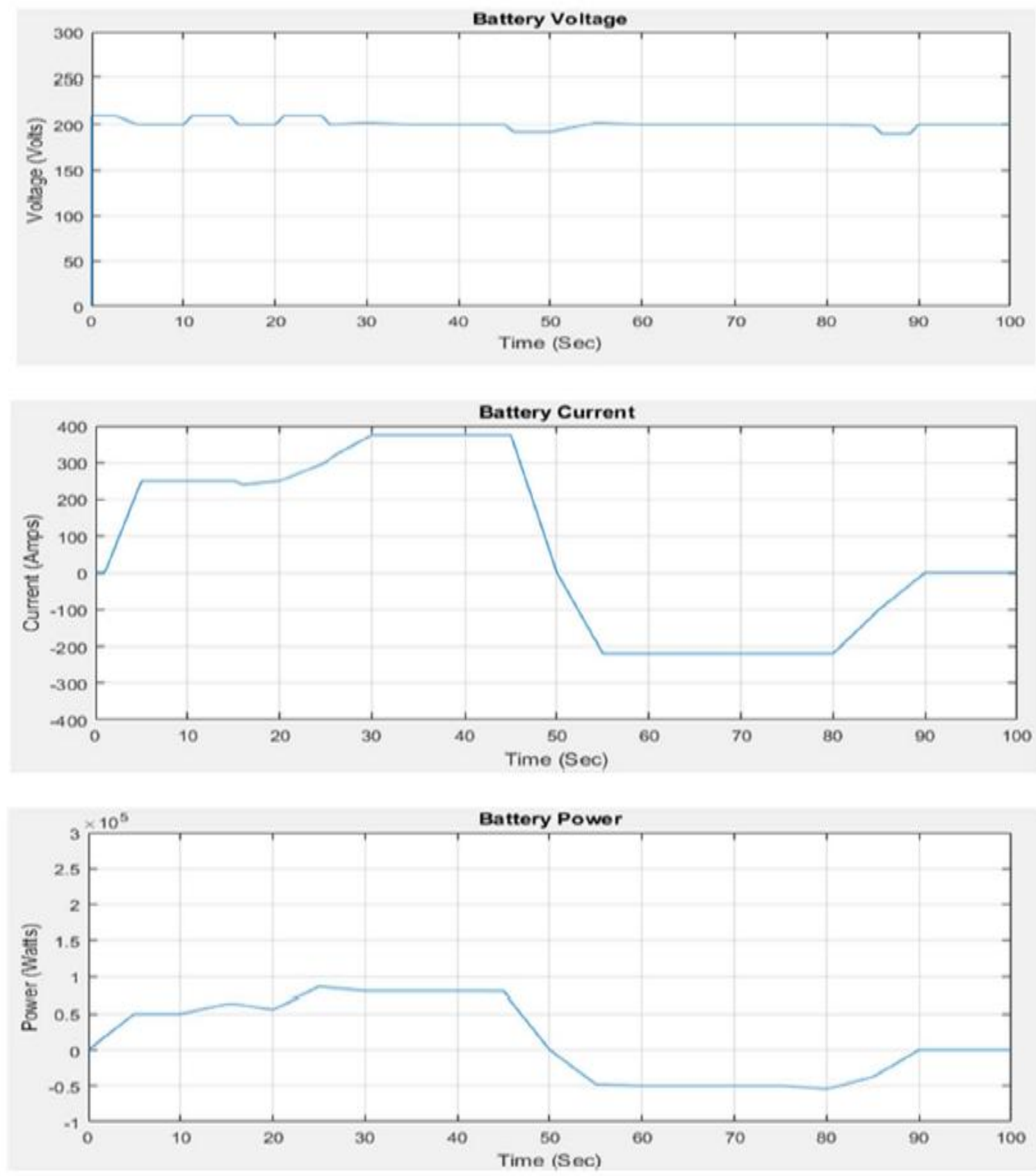

Figure2. Battery Voltage, Current and Power 


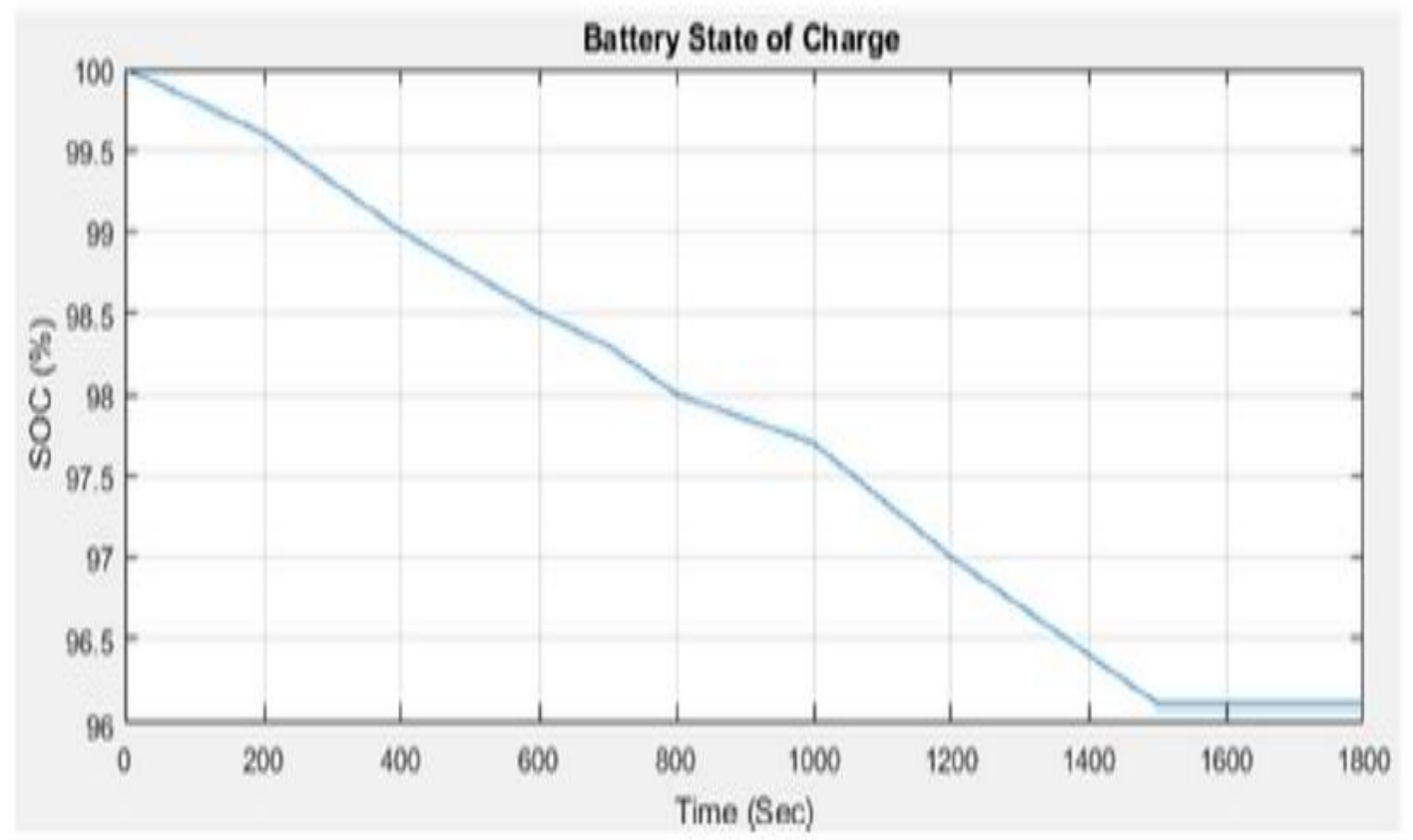

Figure3. Battery State of Charge

\section{Conclusion}

BEV and its components were simulated in this study in to examine the flow, output and efficiency of energy. By using MATLAB-Simulink, good results for battery voltage, current, power, and state of charge were shown. There are still a lot of possibilities ahead to build a better BEV model that will be the basis for future studies. In order to find the best voltage, current, capacity, battery charge state and the exact size of the part, and minimise the for automotive designers, the use of electricity, modelling and simulation are very important

\section{References}

J. Y. Yong, V. K. Ramachandaramurthy, K. M. Tan, and N.Mithulananthan, "A review on the state-of-the-art technologies of electric vehicle, its impacts and prospects,” Renew. Sustain. Energy Rev., vol. 49, pp. 365$385,2015$.

Z. Chen, R. Xiong, and J. Cao, "Particle swarm optimization-based optimal power management of plug-in hybrid electric vehicles considering uncertain driving conditions," Energy, vol. 96, pp.197-208, 2016.

Mohd, T. A. T., Hassan, M. K., Aris, I., Soh, A. C., Ibrahim, B. S.K. K., \& Hat, M. K. (2015). Simulation based study of electric vehicle parameters, 10(19), 8541-8546.

Mohd, T. A. T., Hassan, M. K., \& A. Aziz, W. (2015).Mathematical Modeling and Simulation of an Electric Vehicle. Journal of Mechanical Engineering and Sciences, 8(June), 1312-1321.

https://doi.org/10.15282jmes.8.2015.6.0128.

Meradji, M., Cecati, C., Wang, G., \&Xu, D. (2016). Dynamic modeling and optimal control for hybrid electric vehicle drive train. In 2016 IEEE International Conference on Industrial Technology (ICIT) (pp.14241429).IEEE.https://doi.org/10.1109/ICIT.2016.7474967.

D. Houcque, "'Introduction to MATLAB for Engineering Students," Northwest. Univ. Version, no. August, pp. 3-43, 2005.[7] .Reddy, G.N. 2012. A MATLAB-based tool for EV design. In: 2012 International Conference on Education and e-Learning Innovations (ICEELI).

L. Buccolini, A. Ricci, C. Scavongelli, G. DeMaso-Gentile, S.Orcioni, and M. Conti, "Battery Management System (BMS)simulation environment for electric vehicles," in 2016 IEEE 16thInternational Conference on Environment and Electrical Engineering (EEEIC), 2016, pp. 1-6.

Zhou Bing, Jiang Qinghua, Yang Yi, \& Wang Jisheng. (2010).Analysis of energy consumption and power train parameters optimization of BEV based on running cycle. In 2010 IEEE 11thInternational Conference on Computer-Aided Industrial Design \&Conceptual Design 1 (pp. 1284-1290).IEEE. https://doi.org/10.1109/CAIDCD.2010.5681973. 
Tamilselvi, S., Karuppiah, N., \&Muthubalaji, S. (2018). Design of an efficient battery model using evolutionary algorithms. Periodicals of Engineering and Natural Sciences, 6(2), 265-282. 